\title{
Periodicals Procedure in a University Library
}

Miss Plant is assistant librarian of the British Library of Political and Economic Science, London School of Economics and Political Science.

$\mathrm{T}$ HE INDEX to the Bulletin of the American Geographical Society for 1852I9I 5 devotes five pages of its introduction to a bibliographical note (or an apology for its life). So far, it seems, the bulletin had varied its title six times. The opinions of the editorial board with regard to the second change, from Proceedings to Journal, had apparently been so divided that for a whole year two separate versions of the bulletin were issued, one under each name. Frequency of publication was determined, quite properly, by the amount of suitable material in hand, with the result that while the Bulletin of the American Geographical and Statistical Society had only three numbers in as many years its successor, the Proceedings of the society, issued eight numbers in two years. The Journal began well: in I 859 its first volume appeared, comprising ten numbers; it was followed in 1860 by volume 2 , part I, but volume 2, part 2 was not published until ten years later. Between 1872 and I 877 the annual volumes were issued as New York State documents. From then until i 886 the bulletins bore no indication of their title except on the outside cover, and "during this period the cover of the last issue of each volume bore some such DECEMBER, 1941 statement as 'Nos. 5, I, 2, 3 and 4 of the Bulletin for - , which joined together in the order named, make Vol. — of the Society's Journal'." This publication, in fact, seems to have gone out of its way to harass the librarian. After trying to unravel such a tangle he turns with relief to the type of journal which appears regularly every Punchday.

If a single periodical can make itself such a thorough nuisance, the maintenance of a large collection of them increases the difficulties out of all proportion. "Periodical" is such a wide term. The British Library of Political and Economic Science, for instance, now receives over 4500 titles during the year. Less than half of them are the ordinary weekly, monthly, or quarterly journals of the bookstall. The rest include yearbooks and the reports of government departments, of banks, and of societies, as well as the kind of work which, like the autobiography written too early in life, calls for annual supplements to bring it up to date. And government publications, we may add, can be as tiresome as any. From 186o to 1913, for instance, the Local Taxation Returns for England and Wales were issued as numbered parliamentary papers. The returns for 1913-14 were nonparliamentary papers, except for part 7 , the summary. The summary for 1914-15, too, was a numbered paper, but the full returns were not published at all, nor were any returns 
published for 1915-19. Part I of the returns for 1919-20 was a numbered parliamentary paper, but parts 2 and 3 were nonparliamentary, and none since 1920 have been numbered. Similarly, the Transactions of the American Historical Association were Federal documents before they became unofficial. To keep all of these in the way they should go demands records fully adaptable and yet rapid to maintain.

The first essential is almost too obvious to mention: to decide quite definitely what periodicals one wishes to receive. In the library of the London School of Economics their selection is undertaken, as part of the general intake routine, by the librarian in consultation with the Acquisitions Committee. But from time to time, especially during the springcleaning season, packing cases arrive full of back numbers which the wives of our patrons hope fervently we shall accept. If they fill gaps in our holdings they are welcome; if not, their cost in binding and shelving may be greater than their value to us would justify. Then again, the library seems to be regarded by many editors as a profitable advertising ground for their latest journals. Many years ago large numbers of the sample issues were sent to the shelves as they were received, on the casual assumption that they were to be regular gifts to the library. The librarian, in consequence, was left in ignorance of the new periodicals for which he might well have been anxious to subscribe, the advertiser's aims were defeated, and the record cards for periodicals were swelled by a large number of separate entries for single issues, most of them of doubtful value even as samples. There was every need for the rule now in force - that no card shall be made out for a journal newly received until the librarian has decided whether or not he is prepared to subscribe for the publication, or to accept it as a gift, and has made arrangements accordingly.

\section{Habits of Periodicals}

Unfortunately, matters cannot rest with the simple payment of a subscription or the writing of a letter of thanks. There is little need to remind librarians of the irritating habits of periodicals. We arrange, perhaps, for a year's delivery of a monthly review. During the year it decides not to appear monthly after all, but once every six weeks. An Important Personage comes in one day and asks to see the very issue which has failed to arrive. We decide, now that we have received the whole of the first volume, to send it to the binder; at least, we would send it if only we could find the title page and index. After a time, to put us out of our misery, it announces that it has ceased publication -only to rise to new life after many days in a new form and with a new name. Some of these annoyances are beyond our control. Nevertheless, one of them, late delivery, may be our own fault: why should the newsagent bestir himself if we give him the impression that any time will do? The difficulty in some libraries (including at one time our own) is that the defaulting number is not missed until a reader has arrived, notebook in hand, to consult it.

It must be admitted that the standard five- by three-inch record cards formerly used in this library, and still widely used elsewhere, failed completely to call prompt attention to overdues. Even the tabbing system (which had gradually been abandoned owing to the difficulty of affixing the tabs) had not helped towards imme- 
diate action. Partly this was because attention was fixed upon the wrong thing. The tabs were arranged to correspond with the date last entered on the card. What one really needs to know is something quite different: the date on which the next issue of the periodical falls due.

\section{Variations in Dates}

An example or two may make this clearer. Suppose, for instance, that in December I94I two annuals arrived: one might be the newly published annual report of the department of agriculture of some outpost of the Empire for the year ending June 1940; the other might be Who's Who for 1942. In the first case the date entered on the card would be 193940 ; in the other, 1942. The tab on the first card would be changed to, say, a green one for 1940, and the tab on the other to a blue one for 1942. In neither case was the volume overdue, but how was one to know this? Further, how could one tell which of the yearbooks dated I94 I should already have given place to the next issue?

The same arguments apply to periodicals appearing more frequently. A tab for April I94I would apply indiscriminately to all the periodicals for that month, even though, being issued in advance, they should reach the library in March, or, being part of the regular six-monthly delivery from India, they could not arrive until September. The general inquiry, admittedly, is more likely to be "Has the April number arrived?" than "Has the latest number arrived?" But if the librarian does not know whether the April number was the last he is in a sorry plight.

In the very small library it may be practicable to read each individual marking-off card once a week. In that case full details can quite usefully be written on the card: a remarks column may be used for notes such as "due on the I 5 th of the month," "due on the Ioth of the previous month," "appears fifteen months after the close of the financial year." In the British Library of Political and Economic Science that would be unthinkable. While the standard cards were being used, even after a drastic reduction in their number by the removal of all those for noncurrent periodicals and after a rearrangement of certain sections from classified to alphabetical order, the marking-off process took almost a full day. The nimblest of assistants had not time to turn over all the cards each week and note the missing parts, let alone write for them. So it happened that the gaps not noticed in time became permanent, and volume after volume has to be labeled "incomplete"-the badge of the breakdown of a system.

\section{Installation of Visible Index}

The remedy was not to be found in an increase of staff, even if funds had allowed for such an increase. Two assistants could not have worked at the same time on the one index without considerable rearrangement. As it happened, the change which was actually made has cut down the routine work of the one assistant to a matter of an hour and a half. It was the installation, in 1934, of the now wellknown visible index system.

By this system, on looking for the card for The Economic Journal it is not necessary to turn over dozens of others before finding the right one: one goes straight to the steel cabinet, pulls out the tray marked "E," and glances down the completely visible list. On seeing the wanted card one has only to turn back the cards above (and all cards are on flexible hinges) 
to uncover the complete marking-off card. Opposite this marking-off card is a "facing-card" designed to bear full information as to the publisher and publishing address of the periodical, and as to its source: if it is a gift, from whom it comes; if an exchange, for what; if a purchase, whether it is bought direct or through an agent, when the last subscription was paid, what period it covered, and how much was paid. Space is also provided for remarks, for the binding specification used, and so forth.

Those who have had the unpleasant duty of writing to a donor for missing parts will appreciate the value of having his name and address so close at hand. Records kept in a place apart are fatally easy to lose or apt to be wanting in some vital detail. It is a delicate matter to write to the secretary of a society for an overdue volume of transactions if one is not quite sure whether the publication is a gift from the society or from another donor who happens to be a member of it.

\section{Time Saved}

The time saved by using a visible index has in itself fully justified the initial expenditure. But the real aim was to be able to tell at a glance what periodicals were overdue. This has been achieved by a simple system of tabbing; not, of course, by the old-style tab which took the clumsy a minute or more to fix in place, but by one held in a transparent groove and flicked to its new position in a matter of two seconds. The bottom edges of the marking-off cards have a blank space at each end but are otherwise divided into twelve monthly divisions and five weekly divisions (as there may be five Tuesdays, say, in any one month). In one of the monthly and one of the weekly divisions of each card a green tab has been fixed. In the space at the extreme right a tab of another color signifies a particular year. Taken together these three tabs show, correct to the nearest week, not the date of issue of the periodical part last received nor of the next one due, but the date when the next part is due to reach the library. A black and white striped tab at the extreme left of the card signifies that, owing to irregularity of publication, this date may be uncertain, while the insertion of an orange one shows that, the periodical in question having become overdue, action has been taken.

\section{Examples}

It will be simplest to take some actual examples. On the 12th of October, 194I, the August number of the Australasian Insurance and Banking Record arrives from Melbourne. We turn to the appropriate marking-off card and tick the square corresponding to August I94I, showing that this part has arrived. We then ask ourselves when the next part may be expected. The marking-off card gives the frequency as monthly, so that the next arrival will probably be on or about the 12th of November. We accordingly move the green monthly tab to the November division and leave the weekly tab in the division for the week between the 8th and I 4 th of the month. Take next a weekly periodical, the Law Journal: on the 12 th of October we receive that day's issue. To the October square of the marking-off card, in which the figure 5 has already been entered, we add the figure 12 . The next part is due on the I 9 th of October, so we leave the monthly tab in the October division and move on the weekly tab to denote the week between the $15^{\text {th }}$ and 2Ist. Finally, take the Journal of Social 
Psychology, a quarterly, of which the October issue comes in on this same day: we mark the square corresponding to October I $94 \mathrm{I}$ and, after a quick calculation, readjust the monthly tab to read "January," leave the weekly tab where it is, take out the right-hand-end orange tab representing the year I94I and insert a green one for 1942. The principle is perfectly simple: the marking-off card shows the last part received; the tabs show when the next one is due.

\section{Noting Absentees}

Having by this system finished the day's marking-off by eleven o'clock in the morning, we can set about noting the absentees. Since all the tabs move from left to right, and since the present date is 12 th October, I94I, we can ignore all monthly tabs to the right of the October line. But there may be monthly tabs showing to the left of the October line, or there may be tabs in October with the supplementary weekly tabs to the left of the line for the second week of the month. If so, we want to know why. The first one to the left of the monthly line may be in the February division, but on glancing to the right we find that the year-tab is a green one, for 1942, so that all is well. The next row of tabs may read, "September Ist-7th, I94I :" the periodical is obviously about five weeks overdue, but an orange tab shows that action has already been taken. Only in checking those marked "October" is there any need to notice the weekly tabs: if we read from the tabs that an issue of The Board of Trade Journal should have arrived between the Ist and 7 th of October we insert a red tab to remind us to send for it. On completing the check we look at the facing-card for each overdue periodical to find the name and address of the person from whom the library receives it, send him a reminder postcard, and substitute an orange tab for the red one to show that we have done so. (These specially printed cards are of two different colors to distinguish between purchases and gifts, and their wording is forceful or persuasive according to color). We have now acquired virtue sufficient to fortify us against the most irate reader. If, however, at the end of a fortnight a periodical still remains overdue a letter of inquiry is sent. This may lead to the information that publication has ceased; in such a case the marking-off card and its accompanying facing-card are removed from the index and the words "ceased publication" added to the card in the General Catalogue. The checking for overdues is carried out weekly; the whole process occupies only a few minutes.

\section{Preparing for Binder}

One of the duties of the periodicals assistant is the regular collection of the individual parts in order to send them to the binder. For this purpose it is not sufficient to know that the volume ends with, say, the December issue: the set cannot be bound until the title page and index have arrived, and they may not come in until January or February. There is a danger that, if the assistant is not very careful, and the index is hidden inside an ordinary weekly or monthly part, it may be sent to the shelves unnoticed. Some reminder to the assistant is necessary, and it takes the form of a vertical red line on the marking-off card to show the usual date on which the index arrives. The actual process of marking-off is a reminder to look for the index, and, if it is not there, to write for it.

An additional advantage of a visible 
index has shown itself recently. War conditions might lead to the library's periodicals being delivered to temporary premises elsewhere. To transfer the whole of the marking-off cards would be out of the question, but by taking a photostat copy of each drawer a complete list of the titles of current periodicals has been provided in readiness without any interruption of the library's regular work. The serial number, used for shelving purposes (which does not show in the photostat copy) has been written against each item, so that with the aid of these photographs the work on periodicals could be carried on without confusion.

\section{Index for Annuals}

The visible index would work equally well for annual publications, but as only a single tabbing system is needed for these we prefer to use a separate card index. The cards (six inches by four) are printed on both sides. The front of each card is divided into year-squares to show the date covered by the last issue received, with month-divisions along the top for tabbing purposes. (In practice it is found impossible to forecast exactly when an annual will arrive, so the cards are tabbed according to the quarters in which the volumes may be expected to arrive.) The reverse of the card is designed to bear exactly the same information which is given on the facing-cards of the visible index. Suppose that in October I94I one receives the trade statistics of Canada for the year ending June 1940: the volume will be marked off in the usual way as 1939-40; no change will be required in the position of the tab, as the next report should arrive about one year hence; but, to show that the report due in 194I has been received, the figure " $I$ " is stamped against the entry 1939-40. (This proves to be quicker than changing the tab for one of another color.) Checking for overdues is carried on quarterly by taking note of this figure and of the position of the tab.

The visible index and the annual cards are for the use of the staff. The reader, too, quite often wants to know when a new volume may be expected. For his information all periodicals, all annual and all official reports bear an accession stamp which includes the date of receipt. It is very satisfying to be able to point out to the reader who in January 1941 demands the Annual Survey of English Law for 1940 that the volume for 1939 was not issued until June 1940 (received on the 28th June, 1940); he may be no less impatient of the delay, but his sarcasm will have been diverted to a new channel.

\section{Library's Holdings}

For information as to the extent of the library's holdings of a particular periodical the reader turns naturally to the general card catalog. Unfortunately, this is not yet complete. Until recently periodicals were not cataloged at all, and the periodicals assistant was subject to constant interruption by inquirers. More than half have now been cataloged, but cataloging is a slow process, and as a temporary measure a rough checklist has been compiled. For the cataloging proper a special type of card has been printed to show the room location of current numbers and of bound volumes, respectively, and the serial number.

The entry is made under the present title of the periodical. We quite realize that its name will most likely change again, and that we shall therefore be committed to retyping the main entry and the cross references from other titles; but we also 
realize that by that time rough handling by three thousand readers will probably have made the retyping highly necessary. In any case, we have no desire to be condemned as being behind the times because we enter the current issues under their last title but one! Title entry is adopted for all periodicals other than government publications (which are entered under the name of the country in alphabetical order of issuing departments.) The Journal of the Institute of Bankers, for example, is so entered, with a reference from the name of the institute. As the only exceptions to this rule, "Report" and "Annual Report" are avoided as entry-words; the library contains several hundreds of bank reports alone, so that to concentrate all reports in one section of the catalog would probably cause the reader to turn away in despair. (We ourselves have had a similar experience in trying to use certain otherwise estimable printed lists of periodicals.)

The arrangement of the cards in the catalog is strictly alphabetical, and the runs of periodicals in the various reading rooms are also in alphabetical order. In the reserve stacks it is found more convenient to shelve periodicals according to their accession numbers.

In the typing process two carbon copies are taken of each entry on slips of strong paper seven by three inches, to form sheaf catalogs, one set (with square ends) being filed in alphabetical order as a duplicate catalog for use in emergency and the other (with round ends) being arranged by serial numbers to form a shelflist.
The five- by three-inch cards to which our catalog drawers condemn us will not always allow for a complete statement of our holdings. The complete statement, we have seen, might run into the equivalent of five octavo pages! Rather than use a number of cards for each periodical we prefer to adopt the form "I928 (vol. 7) to date, with gaps," without specifying which parts are missing. To complete the records, in the course of cataloging a loose-leaf register of gaps is compiled. From time to time sections of this list of wanted parts are stenciled and issued to likely donors, newsagents, and second-hand booksellers, sometimes with the happy result that the words "with gaps" can be deleted from the catalog and the entry in the register of gaps withdrawn.

\section{Three Records}

We have, therefore, at the present time, three separate records: the visible index for current use, the general card catalog, and the register of gaps. What we still need is a list arranged by subjects. The reader who casually inquires, "What antislavery journals have you?" little realizes the trouble he causes. It is a difficulty which cannot be finally overcome until all the periodicals are cataloged. When that day arrives we intend to sort one set of carbon copies into main groups (bank reports, chamber of commerce reports, early radical journals, and so on), type each title on a narrow strip, and insert the strips in volumes according to some fully flexible system. Then, so equipped, we shall be prepared for all who come. 